\title{
GENERAL DEBATE
}

\section{Chairman: I. Macdonald, Department of Physiology, Guy's Hospital Medical School, London SE $19 R T$}

Chairman: Before I open the debate, let me remind you that we are debating the question, 'Should recommendation be made to reduce dietary sodium intake?' First of all I remind you that $\mathrm{Na}$ is an essential element in our diet. It is the principal extra-cellular cation. I don't think the topic of whether we should have $\mathrm{Na}$ in the diet or not is for discussion. We must have Na. The other aspect I think that we ought to bear in mind at the beginning of our discussion is that we are concerned more with the preventive than with the therapeutic aspect of $\mathrm{Na}$ intake, if we are going to give community advice.

M. F. Gibney: There is one point that I would like to raise at the outset. It refers to the papers by Dr Beevers and Dr Dodson. They talk about the use of diet in $\mathrm{Na}$ restriction. What Dr Dodson means by a low-Na diet is one with a reduced fat, high fibre, high vegetable protein, low calcium, low available $\mathrm{Ca}$ and low zinc content. My basic point is that it is important that this be stressed at the outset of this debate, that the diet described by Dr Dodson isn't a low-salt diet like the purified diet given to a rat, but a grossly modified diet for human consumption. If we are here today to discuss specifically the issue of $\mathrm{Na}$, we ought to be careful at the outset, to define exactly what we are discussing.

G. Gillett: I've just been back for I year after living in Kenya for 20 years, and perhaps have a little knowledge of what happens when 'tribal man' moves to an urban area. If such people as the Luo need salt to flavour food they use wood ash. Very little salt is available, or used, in rural areas. When a man goes from 'up country' down to a multitribal society I don't think that one can say that it is only an increase in dietary $\mathrm{Na}$ that has affected him, when it comes to hypertension. From my experience in a diabetic clinic, I would say that most of our patients were people who were affluent, or were becoming affluent, who stopped taking exercise, and were taking excessive amounts of European-style beer and sugar. I would not say that $\mathrm{Na}$ is to be regarded as one of the factors in their health problems. More and more urbanized Africans are eating more salt in processed foods. I'm not sure whether they would put some salt in maize flour, because all people who traditionally eat maize flour object to cooking with salt. They are eating much more commercially produced bread, which we all know will probably contain a lot of $\mathrm{Na}$. Bread is being used as a convenience food because of the high price and difficulty of getting fuel, even in quite small rural communities.

Now about the change in the $\mathrm{Na}$ intake in this country over the last few decades. I get the impression every 2 years that I come back to Britain, that more and more 
salt has been added to things. For instance, it is impossible to get potato crisps with a little bit of blue paper. One usually lost most of that salt. I hope that the big companies, like Rank, will give us their old recipes that they used for bread, as we need a lot more information about changes in $\mathrm{Na}$ intake over the years.

Chairman: I take it that you support the case for reducing dietary Na intake?

G. Gillett: Yes, but I would like a little more practical information.

$D$. F. Hollingsworth: Mine is a simple question, asking for clarification. I think the Society has been guilty of a certain amount of chemical vagueness, because this debate is called 'Salt, a risk factor in hypertension', and yet the point of this debate is whether or not we should reduce dietary $\mathrm{Na}$. Now could we have clarification whether we are talking about sodium chloride, or whether we're bothering about other $\mathrm{Na}$ salts in the diet? When we have figures, as in the paper given by $\mathrm{Mr}$ Druce, was he talking about $\mathrm{NaCl}$ or $\mathrm{Na}$ ?

Chairman: Perhaps my colleagues would like to tell us what they were talking about?

E. Druce: The contribution of $\mathrm{Na}$ from salts other than $\mathrm{NaCl}$, is roughly between 5 and $10 \%$ of the total Na. The figure quoted in the USA is about $10 \%$. The figure that was obtained in our own study was something like $6 \%$.

A. F. Lever: I'm talking about Na.

D. G. Beevers: I was talking about salt, but I think it doesn't matter from the point that $\mathrm{Mr}$ Druce made. In practice it is roughly the same thing.

Chairman: But you could be talking about chloride.

E. Druce: I was talking about $\mathrm{Na}$, but I intimated that chloride intake may have effects.

f. S. Garrow: Some of us heard a similar discussion yesterday at the Royal College of Physicians. There I was dazzled by Dr Lever's contribution, but failed to pick up something which I picked up on the 'replay'. He said that it was terribly important for us to know whether $\mathrm{Na}$ restriction reduced blood pressure; it was of less importance to know whether it was involved in the aetiology of essential hypertension. He said, and I accepted it first time round, 'After all, if $\mathrm{Na}$ restriction works, it doesn't matter if it's there in the aetiology'. Surely for today's debate, it really does matter, doesn't it? Would he agree that the question of whether dietary salt intake has relevance in the aetiology of essential hypertension, is important? If this is so would he add this to his proposal for future research? I don't know quite how it is going to be done because we want to find out if a population, who are raised on a modified Western-style diet, which has only had the Na intake reduced, are going to be less likely to develop hypertension as Dr Dodson extrapolated.

$A$. F. Lever: I think other people were less dazzled by my talk yesterday. The bit you quoted was 'Does dietary $\mathrm{Na}$ restriction lower blood pressure?' The bit you omitted was 'and thereby reduce mortality'. The last part of the question is important. The two parts of the question, taken together, are more important than the question of whether dietary $\mathrm{Na}$ restriction lowers blood pressure, which I concede it does. There is no argument amongst us about the ability of dietary $\mathrm{Na}$ 
restriction to lower blood pressure. The argument is about whether dietary $\mathrm{Na}$ restriction is worthwhile in terms of the balance of benefit and harm. We don't have an answer to this, and we ought to get one. We should also consider whether it is feasible to reduce the quantity of $\mathrm{Na}$ in the diet without making it unpalatable. This is an area where members of the Nutrition Society can help.

D. H. Buss: I would like to make two comments. Firstly it may not matter now whether the $\mathrm{Na}$ is primarily from salt or from $\mathrm{Na}$ derivatives. It could matter in the future. One of the things the government, for example, is being asked to do is to allow potassium chloride, which is at present illegal in bread and cheese, to become a major source of salt in some people's diets. The government is being asked whether that restriction can be lifted. Such a change will have a substantial effect on the $\mathrm{Na}$ intake, but it will have no effect on the chloride intake. It is important to know whether dietary $\mathrm{Na}$ or chloride is the 'risk factor' for we are then jumping from one problem to an entirely different one. The second point is that there are two ways in which you can reduce salt intake. One is to reduce discretionary salt, and large amounts of discretionary salt are used by many people all over the country, particularly in the North; the other way is to reduce the salt which is added to processed food. A number of people who seem to be more anti-processed foods than anti-salt, or anything else, seem to advocate this line. It has been said that no harm will result. If, however, $\mathrm{NaCl}$ and sodium nitrite are not used in meat products, there may be no harm from the loss of $\mathrm{Na}$ or salt, but botulism will surely come back.

A. F. Lever: I've heard the argument about the efficacy of $\mathrm{Na}$ as a preservative, and I think that it is convincing historically. If legislation is to replace preservative $\mathrm{Na}$ in foods with potassium, and to keep the anion constant as $\mathrm{KCl}$ rather than $\mathrm{NaCl}$, I would have thought the circumstantial evidence would favour benefit rather than harm. The evidence from 'primitive' and 'Westernized' societies suggests that it is the ratio of $\mathrm{K}: \mathrm{Na}$ that matters most in reducing blood pressure. People have found better correlations of blood pressure with this ratio, than with either $\mathrm{K}$ or $\mathrm{Na}$ alone. The higher the $\mathrm{K}$, the lower the $\mathrm{Na}$, the greater the lowering of blood pressure.

D. G. Beevers: I really don't think I can accept the comment about botulism. All we're asking is that $\mathrm{Na}$ be reduced, let's say to $120-125 \mathrm{mmol} / \mathrm{d}$. We're not talking about eating the same diets as are eaten in tribal societies. If my hypothesis about social class and salt intake is true (and I confess I can't prove that) there's no excess of botulism in this room as far as I am aware!

$A$. F. Lever: We're not asking about discretionary $\mathrm{Na}$ or $\mathrm{K}$. We're asking about addition of $\mathrm{Na}$ to food which is to be preserved from botulism. A lot of $\mathrm{Na} / \mathrm{g}$ food is required for a duck paté, albeit only small amounts of both are eaten. I think Dr Buss has touched on something else which is very important. If we move away from $\mathrm{NaCl}$ as a traditional preservative, we've got to preserve food in some other way. We may, according to Doll and Peto, introduce yet another preservative into food which may give rise to far more serious health problems than those attributed 
to $\mathrm{NaCl}$. Part of the gastric cancer scare focuses on food preservatives that are not $\mathrm{NaCl}$. If there is substance to this worry, and we move more towards these preservatives, our recommendations will do more harm than good.

R. C. Cotterell: Could the panel please correct me if I am wrong, but there seems to be only one study of actual prevention of high blood pressure that has been quoted today. That is the Hofman study carried out on babies in the Netherlands. There are two points about that study. Firstly, after 25 weeks there was $2 \mathrm{~mm} \mathrm{Hg}$ difference in blood pressure between the two groups, which just scraped statistical significance. What is perhaps worth mentioning is that the standard deviation in both of the groups was roughly $10 \mathrm{~mm} \mathrm{Hg}$. Secondly I protest at Dr Beevers' 'crystal gazing' that the fact that there was a $2 \mathrm{~mm} \mathrm{Hg}$ difference at 25 weeks indicates that there would be bigger differences in blood pressure in middle age.

P. M. Dodson: There is some evidence of 'tracking' of blood pressure and serum lipids through life. That's presumably Dr Beevers' point.

$D$. G. Beevers: The whole point in the tracking argument is that you would see continuous separation as subjects get older. I'm unrepentant about 'crystal ball gazing'. I think you are not correct in your comments about the standard deviations. The mean difference between the groups at 24 weeks was $2 \mathrm{~mm} \mathrm{Hg}$, and the $95 \%$ confidence limits were $0.2-0.38 \mathrm{~mm} \mathrm{Hg}$. There was, therefore, a wide separation between the two groups.

R. C. Cotterell: The point about tracking is that of course tracking would be related to those individuals who are in the top decile of the distribution.

$D$. G. Beevers: No. That's not true at all. Tracking has been observed in all people. I deny that as well.

A. F. Lever: When have tracking studies started? At what age?

$D$. G. Beevers: I have to confess that most of them are adult studies.

A. F. Lever: So tracking does occur from a young adult to an old adult. $\mathrm{Dr}$ Beevers is assuming that tracking is also true from a tiny child to adolescence. I think it's been shown in children, but not in neonates. I don't accept Dr Cotterell's point that it only occurs in the top decile of distribution.

Chairman: I think we ought to continue with the broader issues of the debate, rather than this 'nitty gritty'.

E. Druce: Dr Buss was talking about the use of $\mathrm{K}$ as a preservative, as a substitute for $\mathrm{Na}$. The conclusions that were drawn in a very comprehensive study of Sofos, very recently, seem to indicate that $\mathrm{K}$ does not act in the same way as $\mathrm{Na}$ does as a preservative. Its mere substitution therefore could, at this moment of scientific knowledge, not necessarily exert the same degree, or even the same pathway, of preservative action.

P. G. Burstyn: I would like to refer back to the mention of Africans consuming a low-salt diet. We have some reasonably good studies on people who migrate from rural areas to urban areas. These studies neglect the fact that most Africans who migrate, do so 'solo'. They are males who leave their children and their wives behind in the rural areas. Thus a great deal alters in their lives, apart from the $\mathrm{Na}$ intake. 
At least 6 years ago in Finland they introduced a $\mathrm{Na} / \mathrm{K}$ mixture to replace table salt. I wonder if any studies have been carried out now to detect whether this has had any effect on the blood pressure?

Finally I am curious why nobody ever mentions, when salt and blood pressure studies are considered, the water intake; surely it makes a big difference whether you are an experimental rat taking in your $\mathrm{Na}$ in a way that you cannot avoid, as hypertonic saline, or whether you are the other sort of experimental rat who has $\mathrm{Na}$ given to you in the form of food, when you can drink all the water you wish to slake your thirst.

$A$. F. Lever: On the last point, we did the experiment both ways round. We put the supplementary salt into the food in one study and, in another, into the drinking water. In both studies there was a tenfold difference of dietary intake and blood pressure was lower in the control groups. Putting salt into drinking water is the more unnatural route, I agree.

E. Druce: Can I take up the discretionary salt issue which was just raised? I think that in Finland, out of the ${ }^{10-1} 5 \mathrm{~g}$ intake/d, 4 or more grams were taken as discretionary salt. The $3 \mathbf{g}$ that is often quoted for the UK is an average which includes other non-dietary uses of salt such as keeping the snow away.

$A$. F. Lever: Could I ask Dr Burstyn if he thinks that it is unfortunate that nothing was done to check blood pressure after a major dietary alteration such as that which took place in Finland?

P. G. Burstyn: I'm curious why it has not been reported; why the opportunity was not seized.

$A$. F. Lever: Has it been seized? I don't know.

$D$. G. Beevers: There is a study from Finiand where there was a Na/K salt and all the Finns thought 'This is good for us', and ate vast quantities, and increased their $\mathrm{Na}$ excretion. I don't know what happened to the blood pressure.

E. M. E. Poskitt: From what has been said in the debate so far I feel it might clarify things if we look at the possibilities available. I think things like botulism are confusing the argument. What we could do is firstly recommend that the population takes less salt on its food, and uses less in cooking. Secondly we could recommend that manufacturers reduce the salt they use in foods, or alternatively we could recommend that the government brings in legislation to make manufacturers use less salt in food. I would have thought the last suggestion is certainly out on present knowledge. I would have thought that on the second, we probably don't have sufficient evidence at the moment, and therefore we should be arguing about whether or not we should recommend that the population reduces the salt it takes with its food. As someone who doesn't use salt in cooking or on food, I can say that it's perfectly possible to eat such a diet.

With regards to the Hofman study; DeSuite looked at blood pressure in babies. He had babies on a much higher salt intake than Hofman because the study was pre-1975, when babies were basically being fed on cow's milk. As far as I know he didn't find a difference in the blood pressure of those babies, and those who were on breast milk, which contains much less salt. This is rather in contrast to the Dutch study. If one is thinking about legislation to change $\mathrm{Na}$ intake, it's worth 
bearing in mind that almost overnight in 1975 we changed the salt intake of babies by dropping it to about $33 \%$ of what it had previously been, because the evidence against cow's milk was so strong on totally different grounds.

D. G. Beevers: The DeSuite study is a comparison of two different groups in what was in a sense a natural experiment. It isn't quite the same thing as the Hofman study which was a randomized trial that gave more reliable information. It doesn't deny the DeSuite finding at all, because his groups were not concordant for blood pressure in both spouses, which Hofman controlled for.

P. M. Dodson: On the subject of the effect of cutting out salt at table and in the cooking, I was surprised by what occurred in experiments that we are doing. One group we're studying has managed to halve its $\mathrm{Na}$ intake. I'm amazed at how much more salt the population is taking than was realized.

A. F. Lever: How much is the salt intake of your subjects likely to be?

P. M. Dodson: Mean values for our low-Na diets are about $110 \mathrm{mmol} / \mathrm{d}$ which is well into the sort of range that produces hypotensive effects. Admittedly one would accept Dr Gibney's point. These are of course multiple interventions, but I think it is that sort of reduction in $\mathrm{Na}$ intake which is easy to achieve and effective and would not result in botulism becoming rampant in the community.

G. Wright: I'm pleased to say there is one thing which is becoming clearer this afternoon to me, and that is that one should have to vote against the motion that recommendation should be made this year to reduce dietary Na. I think it's far too early to say. Now if the debate was 'Should we vote in 1990 . . .' by then we may be in a position to be able to make such a recommendation. Dr Lever does himself an injustice when he says that yesterday at the meeting at the Royal College of Physicians on salt and hypertension all his colleagues were up in arms against him because, to an observer, that wasn't really the case. No clear consensus or conclusion came from that discussion, which was attended by cardiologists, epidemiologists and many eminent physicians, other than that more work needed to be done. There was a general feeling that in hypertensive patients, a reduction in dietary $\mathrm{Na}$ may lead to a reduction in blood pressure, and therefore might be a good thing. That was about as far as anybody was prepared to go. I feel that the present debate is premature by about 5 years, and that we need more information before we can make recommendations, not just to hypertensive patients, but to the rest of the population. So as I say, there is only one way to vote.

D. B. Beevers: I'm going to disagree with you obviously because I'm here to do that. There's a standard rule in the British Medical fournal that any paper that ends up 'Further research is necessary' is always routinely rejected. Let us say that we devised some rather clever study on a mass basis in which we were to salt deplete a very large population, and had a control group. The problem would be that the dietary salt consumption in the country in adults is probably falling. A similar problem will arise, as in the 'Mr Fit' study which I mentioned earlier. In that study they randomized the population to receive intensive dietary advice, while the controls did not. At the end of 5 years they found no difference between the subjects. The reason for that was probably that the 'Mr Fit' group did well, but 
the control group, which we might call 'Mr Slob' also did well. Dr Lever wants yet another study because he likes studies, and I think we might end up with an answer that would satisfy nobody. That is why I'm afraid that the study that he wants, and which I want too, is probably going to be confounded from the start.

$A$. F. Lever: How can we prejudge the results of a study which is not yet started, and not yet designed? I'll design one if you like. It is better to proceed that way than to continue in total ignorance of what we are recommending to the public.

D. G. Beevers: But in that case you would not have destroyed the Broad Street pump.

A. F. Lever: Of course I would. Removing the handle of the pump was the experiment that I would have favoured at that time. The departure of cholera when the handle was removed was exactly what one would have predicted if the pump were the cause of the illness.

Chairman: Did you want to come back on that Dr Beevers?

D. G. Beevers: No.

f. C. Mathers: Dr Lever got us a little bit worried about having low-salt diets on the basis of some rat experiments that he carried out. I may have got the data wrong, as they were shown rapidly. Perhaps he will correct me, but my impression was that he wasn't comparing high-salt diets with moderate-salt diets, but moderate-salt diets with deficient diets. From my impression, his $\mathrm{Na}$ intakes were extremely low; the sort of levels that we expect animals to be unwell on, and there is nothing unnatural about that, and the fact that they didn't survive surgery was exactly what you would have expected on deficient diets.

$A$. F. Lever: I don't agree with you. Let me give you the figures. The rats were on a normal diet in the control period, and were switched to a diet which was ten times lower in $\mathrm{Na}$ content. This was the equivalent of a man changing from 170 to I $7 \mathrm{mmol} / \mathrm{d}$. Both Dr Beevers and $I$ have been on diets lower than this latter amount, and we were certainly not ill as a result. If surgical mortality in the rats increased with this dietary change by tenfold how do we know that it is not going to increase threefold with a lesser dietary change? I don't believe that things in biology happen as all-or-none phenomena. To see a change with extreme $\mathrm{Na}$ depletion doesn't necessarily imply that we are not going to see a bit of change with lesser degrees of $\mathrm{Na}$ depletion.

On the question of Dr Beevers' claim that all studies in rats should be discarded.

$D$. G. Beevers: I didn't say that at all; I said 'I'm not a rat'.

A. F. Lever: Most of us accept that you're not a rat, but rats are very useful. If all studies in rats are to be discarded, there would be little information for the Safety of Medicine Committee, which depends for licensing of drugs on toxicity studies in two different species, one usually the rat. Of course there should be studies in rats, and we should look at the results.

f. C. Mathers: I wasn't arguing against rat experiments. It was simply to try to get into perspective the $\mathrm{Na}$ concentration of the diets. I recall that you gave I $\mathrm{mmol} \mathrm{Na} / \mathrm{kg}$ diet, which is extremely low for a rat diet.

$A$. F. Lever: It is not extremely low for a rat. It was down to I $\mathrm{mmol} / \mathrm{kg}$ rat, 
which is $0.2 \mathrm{mmol} / \mathrm{rat}$. A normal rat in our lab eats roughly $2 \mathrm{mmol} \mathrm{Na}$, which is a lot more per $\mathrm{kg}$ than a normal man.

7. C. Mathers: I'm sorry, I misunderstood. I thought it was per $\mathrm{kg}$ of diet.

Chairman: I think the speaker is raising a good point. You can of course kill rats or anyone if dietary $\mathrm{Na}$ is too low. Was your $\mathrm{Na}$ too low? As you say it wasn't your surgical techniques which killed the rats.

A. F. Lever: It was low enough to produce other changes but it was compatible with the rats' survival. It was enough to prevent them gaining weight normally, so they were just below the limits of normality. They weren't in a healthy state.

f. C. Mathers: What strain of rats were they?

A. F. Lever: They were Sprague-Dawley males.

f. C. Mathers: Did they show signs of atrophy?

$A$. F. Lever: We didn't look. You would expect it, would you?

f. C. Mathers: Yes.

$A$. R. Michell: It was said earlier, and I think correctly, that the emphasis here has to be on prevention and not therapy. The one fact that sticks out a mile from the weak epidemiological data, whatever the problems, is that there is not a single exception to the rule that a 'low salt' culture does not have the age-related rise in blood pressure which we all tolerate as normal in Western societies, nor do they have an incidence of hypertension. The common thread that runs through those diverse 'low salt' cultures is their low $\mathrm{Na}$ intake. I don't think there is any other common factor. The second point is the question of risk. I think we're getting into desperation in quoting the risk of botulism, and rats that cannot be cannulated without dying. There is a published requirement for the rat, based on a body of scrutineered evidence. It is published by the National Academy of Sciences. It rests on good evidence, and until suitable rebuttal is published in detail, we have to depend on it. It says that the Na requirement of the rat, even for pregnancy and lactation, does not exceed $0.05 \% \mathrm{Na}$ in the diet, which scaled up to man is of the order of $70-150 \mathrm{mmol} / \mathrm{d}$. Therefore Dr Lever's low-salt rats are on requirement. His high-salt rats are indeed on high salt. If he has problems with his cannulations it could be due to the $\mathrm{K}$ in the diet, which is important. It could be a question of whether the cannulations were done as a double-blind study. Above all don't let us take anecdote against published evidence on the requirement for $\mathrm{Na}$. Very revealingly, Dr Lever mentioned in passing that he thought salt restriction would be no better than $\beta$-blockade. But $\beta$-blockade is expensive and unpleasant, as anybody would see from an article in the Lancet about 6 years ago, by a physician who was actually subjected to it. The question of acceptability of a low-salt diet has been argued in the wrong terms. Of course if you've grown up with 'fast foods' you will not like such a diet. However, if you've educated your children, as much as possible, to take a low-salt diet, the evidence, both from humans and from animals is that the less $\mathrm{Na}$ you are accustomed to in your young life, the less you'll expect in your adult life. It is a contentious subject. The correct verdict is the old Scottish proverb of 'not proven', but something follows from that. Mr Druce has already told us that our discretionary salt is even less than we thought it was, because he's 
left the manufacturer's salt where it was, and said that the discretionary salt is rather less. Thereby lies the problem. The public has the right to make its own decisions in the light of the evidence. It cannot easily do that while it is only in control of a fraction of its own salt intake, a third or less in terms of discretionary salt. It is necessary that the food industry labels its products, that the public is encouraged as far as it can to lower its $\mathrm{Na}$ intake, and that the food manufacturing industry, as far as it can, is encouraged to think twice about the uses to which it puts salt. We heard the 'there is no alternative' argument from Mr Druce, but there is usually an alternative when there is an incentive to find one.

Chairman: Well, there are two dogmatic statements. Would you like to pick them up Mr Druce?

E. Druce: I think it has to be said that the food industry currently has responded in a very positive way to the potential of nutrition labelling. It is quite well known that the Ministry of Agriculture, Fisheries and Food, industry, and others concerned have been considering these possibilities. On the question of the provision of alternative foods, I think there are certain moves to make sure that if it is necessary to increase the consumption of special foods in relation to dietetic needs, then salt content should be watched. I think this has been done. There are many products that have been made with reduced salt, or even no salt. There is also on the market a 50:50 mixture of $\mathrm{K}$ and $\mathrm{Na}$ for discretionary use. There have been attempts to introduce 'salt free' canned vegetables, and there may be many other foods which are future candidates for this sort of treatment. There is one golden rule though about foods. People who are not ill will only buy the foods they like. I think it is unfair to suggest that salt is added by food manufacturers to food, just for the sake of it. It is added, apart from the potential technological reasons, for flavouring. If salt was over-added for products sold on a national market, then that would be as bad, from a point of view of sales, as not flavouring it at all. I would not dispute that a long-term salt hunger can exist. Nonetheless, in real terms salt had to be added to food in quantities which the public will like and buy. One of the things that has depressed me in this debate, and during yesterday's conference at the Royal College of Physicians, is that one might be confused into thinking we are talking about pollutants, pesticides or poisons. We're actually talking about salt, and about food. One of the things we have to bear in mind is that a great deal of stress would be caused if we didn't like what we ate. People who are healthy eat a wide variety of foods, because they like them, and because they do them good. I think primarily you must never lose sight of the fact that healthy people are in the majority, and healthy people do demand fun, enjoyment and variety. There are other nutritional problems that can arise if we just manipulate the diet in terms of $\mathrm{Na}$ with tunnel vision.

$A$. R. Michell: Sheep are rather interesting animals from the point of view of $\mathrm{Na}$ metabolism. Their requirement is below $10 \mathrm{mmol} / \mathrm{d}$, including pregnancy and lactation. I think one of the problems for the human physician is that they are blinded to the exorbitance of human salt intake because they are insufficiently aware of actual mammalian $\mathrm{Na}$ requirement in other species. 
A. F. Lever: Could I come back on that? I think Na requirement of an animal per $\mathrm{kg}$ depends on the size of the animal. The bigger the animal, the less it needs per $\mathrm{kg}$ and, as with other measurements, it may be better to relate intake to body surface area.

$D$. G. Beevers: Dr Lever has made the point that we are healthy. The whole point is that we are not healthy. The UK population has almost the highest heart disease rate in the world. The rate in Finland had fallen sharply.

P. M. Dodson: Can I make a point about what you said earlier Mr Druce. I take total issue with you about palatability of low-salt foods. I think it is fine that you have this idea that you are eating tasty foods and enjoying life. Certainly one would imagine that the creator brought us into the world to do this. However, I think that experience with changing diets has shown that after a period of time people adapt extremely well. Not everybody, but a good proportion of patients actually find the types of regimens we recommend preferable to their previous ones. The idea that these diets are totally hopeless for the population as a whole should not be thrown out of the window by any manner of means.

M. Ashwell: Dr Lever made a very good point, right at the beginning of his talk, which he re-emphasized in the discussion. He said that he doesn't doubt that dietary $\mathrm{Na}$ restriction brings down blood pressure. But he gave us a couple of examples where it didn't seem to reduce morbidity and mortality down to control values. I don't think we've quite heard Dr Beevers' reply on that particular part of the discussion. Could Dr Beevers tell me how he interprets those particular trials that $\mathrm{Dr}$ Lever quoted, and does he have any other evidence that $\mathrm{Na}$ restriction does reduce mortality and morbidity?

D. G. Beevers: Reducing blood pressure by pharmacological means in patients, which is rather a separate issue, does not normalize risks so that if your blood pressure is reduced to $90 \mathrm{~mm} \mathrm{Hg}$ by some drug, you're worse off than if your blood pressure is naturally 90. Dr Lever has shown that, by comparing the Glasgow blood pressure clinic patients with the population of Paisley. A similar thing was also shown in the Australian national high blood pressure study. I would have been surprised if it had normalized risk, as cardiovascular disease is something that has been developing for $3^{\circ}$ years before it clinically presents. Marked atheroma was found in soldiers who were killed in the Korean War. The idea that a short-term 2 week or 3 week trial, done at the age of 45 or 50 , is going to normalize cardiovascular risk is probably naive. It certainly reduces it, but I'm not surprised that is doesn't normalize it.

$H$. M. Sinclair: We were shown a curve of the fall in strokes since 1930. The fall was steady and introducing drugs in 1954 made no difference. There was a fall going on in cholera long before John Snow tampered with the handle of the Broad Street pump, and that made no difference to the fall. That's trivial. Much more important, we're debating 'Salt, a risk factor in hypertension' and there's one dietary factor that greatly alters the risk of salt, if there is a risk. That is the type of fat in the diet. There have been many papers published about this. Now we've been told by Dr Beevers and Mrs Gillett, about the Luo maize-eating people 
migrating to Nairobi. There are people who have altered their diets without migrating or leaving their wives behind. They are Eskimos, who are known since 1927 to have had a low blood pressure. But as was recently shown, when they became Westernized and altered the fats in their diet, their blood pressure increased enormously. Admittedly they ate other things. There have been three trials of altered polyunsaturated:saturated fatty acid ratios in which blood pressure has changed; for example, the national diet heart study in 1968, in which admittedly cigarettes were also decreased. The polyunsaturated:saturated ratio was increased and blood pressure fell. There was the 'anti-coronary club' study in which cigarettes were not altered; polyunsaturated:saturated ratio was increased and the blood pressure fell. In the Heidelberg study, it was shown that there was an inverse correlation between linoleic acid in adipose tissue and blood pressure. The higher the intake of linoleic acid the lower the blood pressure. This observation is being borne out by a great many studies in rats. There have been six or seven studies in which it has been shown that linoleic acid inhibits 'salt-induced' hypertension in rats. We think we know how this occurs. It has been shown in salt-sensitive rats that prostaglandin $E_{2}$ production from arachidonic acid in the renal capillaries was significantly lower than that in insensitive rats. Arachidonic acid comes from an essential fatty acid. I think, therefore, that the type of fat, whether it is polyunsaturated or saturated, is extremely important in deciding whether or not salt is a risk factor in hypertension.

Chairman: So that for every teaspoon of salt, you should have a teaspoon of arachidonic acid to counteract its effects?

A. F. Lever: I think that what you say is probably a lot more important than the salt issue. Apart from the trials you mention, there are two recently published papers where reversal of atheromatous disease has been achieved. It is the first time I think that the disease has been reduced by dietetic means alone, so we have a real focus for a dietetic recommendation. So I agree with what you say.

P. G. Burstyn: I'd like to mention something about quantities of salt given in animal experiments, and those found in human diets. The early experiments with rats required the 'human equivalent' of around $400 \mathrm{~g} \mathrm{salt} / \mathrm{d}$ to make them hypersensitive. As far at the human requirement for salt is concerned, a naturally occurring diet has not been found that has caused a man to be hyponatremic. The realistic minimum for human consumption is around $\mathrm{I} \mathrm{g} \mathrm{NaCl} / \mathrm{d}$ if you are just a grain eater. While we're moaning about the epidemic of this disease, we should remember that our 'high salt, high fat, high energy, low fibre' culture, and our living in a polluted environment is associated with a regular, steady prolongation of life span.

A. F. Lever: Yes. The expectation of life in $187 \mathrm{I}$ was 41 years.

P. G. Burstyn: That's why I'm not convinced by the high-salt argument.

A. F. Lever: I'm not suggesting that dying at $4 \mathrm{I}$ is a consequence of salt intake. I am suggesting that there is a Ruskin/Gaugin syndrome, a wish to revert to primitivity as an ideal as something totally admirable medically and in other ways. 
P. G. Burstyn: Life expectancy is now greater in Eskimos despite high blood pressure. They live longer, now they're chronically alcoholic.

D. G. Beevers: Can I disagree about that? Coronary heart disease in this country has risen steadily since the war. There is some evidence that it may have levelled off, and might just have fallen over the last year or so. The fact remains that the UK is one of the unhealthiest nations of the West, whereas ro years ago the Americans had much more heart disease that we did. They now have much less. The average life expectancy of Americans has risen. We have everything to be rather concerned about. Even within this country, if you compare North with South, Scotland with England, for example, there are still differences in incidence to be seen which are very worrying. I therefore cannot accept that we are healthier.

Chairman: I think there's a catch in your figures. You talked about life expectancy. Lots of things have contributed of course to our increased life expectancy. Infant mortality has decreased, tuberculosis incidence has decreased and we have antibiotics. So I don't think you can say changes in our diet have got anything to do with it.

P. G. Burstyn: The best correlation between coronary heart disease and anything is the life expectancy. As the life expectancy goes up, and the number of aged people in the society increases, so does the coronary heart disease.

Chairman: Not the incidence though.

C. Hunt: I'm getting slightly confused because I thought if salt was a risk factor for anything it was for cerebrovascular disease, i.e. strokes, rather than coronary heart disease. For example, I wonder if the panel have any comments on the strange situation in Japan, where there is a high incidence of strokes, and a low incidence of coronary heart disease.

D. G. Beevers: Your point is well taken. It is strokes certainly, but high blood pressure is an important risk factor for coronary heart disease as well. One would expect to see some effect of salt on coronary heart disease, although not as dramatic as for strokes. Strokes and high blood pressure are so closely related that one can almost superimpose the change of incidence of the two. When it comes to coronary heart disease and blood pressure there is a relation, but it is a much weaker one because there are confounding variables like blood lipids and cigarette smoking.

$R$. N. Clowes: As a humble dietitian talking to hundreds of school children, do I continue to tell them to eat less salt ? Some of them are eating up to five packets of crisps a day. Or do I say wait another 5 years until we have done a bit more research?

Chairman: This is obviously a popular question. Please would you all give an answer.

A. F. Lever: I think I would probably say 'cut down on the crisps' but I would make no public proclamation of the sort the Nutrition Society might issue, saying that it is now clear on the balance of evidence that eating five packets of crisps per day is bad for you. Recommendations from committees and societies sometimes have an undeserved air of authority not justified by the evidence. I do sometimes 
advise patients to reduce dietary salt, particularly if they have 'kidney failure' type of hypertension, and it works.

Chairman: But we're not talking about patients. We're talking about 'the man at the top of the Clapham omnibus'. Would you advise him to reduce his salt intake?

$A$. F. Lever: Yes, but I wouldn't go to the top of the bus and shout at him. If he came and asked me, I would probably say it does do some good.

Chairman: If he said would it do me any harm if I reduce my salt, what would you say to him?

A. F. Lever: I would say 'Frankly I don't know, it's very unlikely indeed'.

Chairman: How do you go along with that Dr Beevers?

D. G. Beevers: Yes. I would advise all people. I'm worried about the salt intakes of children in particular. Mrs Clowes' point is well taken. I think we should do all we can to stop our children taking the vast quantities of salt that they are.

A. F. Lever: Does it look as if I've got double standards?

$R$. N. Clowes: Yes.

A. F. Lever: I thought it might look like that. I believe the difference is between a pronouncement from a committee that carries authority of something proven or not proven, and the hunch of a doctor in managing a particular patient.

Chairman: I'm almost getting excited that we might have a consensus. What do you feel about it?

A. F. Lever: I think it's a deadly danger having a consensus.

$G$. Gillett: One question that hasn't been touched on. Is there any genetic factor? We know with diabetes that some tribes who change their way of life become diabetic very readily. I would like to know if there is a genetic factor for sensitivity to $\mathrm{Na}$ as far as hypertension is concerned.

P. M. Dodson: I think there probably is. There is evidence that diabetics have an increase in exchangeable $\mathrm{Na}$. There is an erythrocyte $\mathrm{Na}$ defect. When exchangeable $\mathrm{Na}$ is normalized, blood pressure falls. I think the diabetic is a good example where $\mathrm{Na}$ is probably a particularly prominent risk factor for hypertension.

A. F. Lever: I think so too. There is a genetic element in hypertension and in salt-sensitivity to hypertension in animals.

D. G. Beevers: We have studied this problem. Peter Weisberg has just done a study where he $\mathrm{Na}$ depleted, then $\mathrm{Na}$ loaded and then $\mathrm{K}$ loaded a group of medical students, half of whom had a strong family history of hypertension, and half with no history at all. He measured the blood pressure of all the parents as well. He found no difference in the salt sensitivity of the medical students. Their blood pressure fell when he $\mathrm{Na}$ depleted them, and rose when he $\mathrm{Na}$ loaded them. Their blood pressure fell slightly with $\mathrm{K}$ loading on top of $\mathrm{Na}$ loading, but the difference between the two groups was not statistically significant.

P. M. Dodson: The British Diabetic Association is currently recommending a diet more stringent than the NACNE proposals. I can't see any evidence of harm from this diet, and now it's been in force for 5 years. We're routinely telling diabetics to cut out their added table salt. The idea that we're doing a lot of harm I don't understand at all. 
Chairman: We've almost agreed about $\mathrm{Na}$. How about you Mr Druce?

$E$. Druce: On the issue of whether we should or should not reduce salt in the diet, I'm strictly a layman. It is really a question of the medical risks, the medical benefits and their evaluation. As somebody who works in the food industry I think it would be foolish for us to both give advice and take advice. This is the essence of the debate: risks, benefits, and the advice that is to be given. One thing that does emerge, consensus or no consensus, is that it isn't a simplistic message. It isn't 'reduce salt and everything will be good for everybody'. The problem is that whereas we can have a debate like the present one today, the extrapolation of this sort of thinking by the media is much more polarized. It does become a cause and effect situation. It is to this which I believe we owe to the public to give a balanced view and not purely a distorted view.

D. G. Beevers: I'm not going to let you get away with that, you see, because you're a layman. We need your view. Armed with the facts you roughly have, would you like to give advice to the dietitian who has just asked 'What do I do with the little girl who eats five packets of crisps a day?'

E. Druce: I would look with horror at someone who eats five packets of crisps a day. On the other hand that is not a licence to say to the community at large 'reduce salt simpliciter', because there are plenty of people who don't eat five packets of crisps a day, who probably eat far less salt than the published averages, who may take that advice as well. It is these people who should be given the balance of the argument, and not just one side.

Chairman: Mr Druce, I must confess that as 'the man on top of the Clapham omnibus' in the room here today, you can't help but be impressed by the evidence that has been put forward, that you should reduce your salt intake. Isn't that what everyone seems to be saying? Even Dr Lever is saying it.

$A$. F. Lever: No I'm not saying that. It would be quite fun to have a vote.

E. Carlson: This is a comment on a point that Mr Druce made earlier, based on the fact that industry must put salt into food, because the community wouldn't buy the food otherwise. This is much the same argument used against supplying wholemeal bread or skimmed milk a few years ago. We've seen quite a change there.

R. C. Cotterell: I must congratulate the 'humble dietitian' for having taken this discussion totally from scientific debate into forcing a conclusion when all the arguments did not allow for a conclusion. In my view the scientific approach to this debate is to say 'Does the evidence merit a conclusion?' not 'You must come to a conclusion yes or no' and that's what we've changed in the last 10 minutes, and we've changed totally the atmosphere of this debate. This is precisely the reason I voted against these debates when the questionnaire came round from the Nutrition Society, because I think it militates against the Nutrition Society as a Scientific Society.

$A . F$. Lever: I agree with that.

R. F. L. Allen: In quite a different context the late Bishop Henson warned against fraudulent certainty, and before we cast a vote in any particular direction, 
just bear that in mind. The ethical responsibility of the Society is to avoid fraudulent certainty, and I for my part, having listened to this debate, cast my vote 'not proven'.

Chairman: Last question.

P. G. Burstyn: The scientific evidence doesn't convince me that $\mathrm{Na}$ is a hypertensive substance, but we're asking the wrong question. We seem to be asking whether we should reduce the amount of $\mathrm{Na}$ that is supplied to the public. In fact the question we should have asked is 'Why have we allowed it go up?', because there was no need for it.

Chairman: I must bring the proceedings to a close, as we've run out of time. I'm not going to take a vote because if the majority go one way or the other you'll never know how it might be interpreted by the media.

A. F. Lever: Yes I think that's true.

Chairman: Finally I'd like to thank very much the speakers and those participating in the discussion for what $I$ think has been really rather an interesting, exciting debate. We've moved away from the topic, but we have come back to it in the end. We have a sort of general consensus with which some people will disagree, if I can put it that way. I think the Programmes Committee is to be congratulated on organizing today's programme. 